\title{
LUT
}

University

\section{The Dilemma of Organization in Social Movement Initiatives}

\author{
Laamanen Mikko, Bor Sanne, Hond Frank den
}

This is a Final draft

version of a publication

published by Cambridge University Press

in Organization outside Organizations: The Abundance of Partial Organization in Social Life

DOI: $10.1017 / 9781108604994.014$

Copyright of the original publication: (c) Cambridge University Press

Please cite the publication as follows:

Laamanen, M., Bor, S., Hond F. den. (2019). The Dilemma of Organization in Social Movement Initiatives. In: Ahrne, G., Brunsson, N. (eds) Organization outside Organizations: The Abundance of Partial Organization in Social Life. pp. 293-317. DOI: 10.1017/9781108604994.014

This is a parallel published version of an original publication. This version can differ from the original published article. 
Mikko Laamanen, Royal Holloway University of London, mikko.laamanen@rhul.ac.uk Sanne Bor, Hanken School of Economics and LUT University, sanne.bor@hanken.fi Frank den Hond, Hanken School of Economics and VU University, frank.denhond@hanken.fi

Social movement initiatives are distinct from social movement organizations (Zald \& Ash, 1966; McCarthy \& Zald, 1977); participants in social movement initiatives do not want to emulate the decided social order that is typically found in social movement organizations and, more generally, in formal organizations. These initiatives are collective action groups that experiment with horizontal, non-hierarchical forms of organizing. In this chapter, we present a case study of such a social movement initiative, illustrating the persistent, everpresent dilemma of organization inherent in horizontal organizing. We see the organizational question not as whether organization affects social movement initiatives, but as how their participants attempt to organize in ways that are reflective of their ideals (cf. de Bakker, den Hond \& Laamanen, 2017; den Hond, de Bakker \& Smith, 2015). With a focus on the production of organization, we develop our argument about the tensions between horizontal organizing versus bureaucracy (i.e., the introduction of hierarchy and rules), and horizontal organizing versus oligarchy (i.e., the usurpation of social order by a few). These tensions are central issues in the emergent theorization of partial organization (cf. den Hond et al., in this book).

Our empirical analysis centres on timebanking. A timebank is a group of people that maintains a local complementary currency system and engages in social movement activity by challenging the prevailing hegemony, not only in its political and economic dimensions, 
but also in its associated cultural dimension (Eskelinen, 2014; Laamanen, Wahlen \& Campana, 2015; North, 2014). In banking time rather than the national currency, timebankers create alternative, non-monetary currency systems in seeking to transform markets and social interaction. Many, if not most timebanking initiatives eschew formal organization. Central to their projects of showing how an alternative to the current hegemony can be viable is the concept of horizontal organizing or, in short, horizontality: 'the continuous process of challenging the centralization of power to attain as much equality as possible between actors' (Maeckelbergh, 2011: 2). Yet, the experience of timebankers is that it is well nigh impossible to rely solely on the emergent social order in their organizing. For this reason, timebanking is a particularly illuminating case for exploring the challenges of organizing a community that attempts to meet the mundane needs of its membership, while practicing horizontality and aiming to change society in political, economic, and cultural terms.

The question we focus on in this chapter, therefore, is: How have the participants in a timebank attempted to resolve the dilemma of needing, but not wanting to have, a decided social order? Our analysis draws on the experiences of participants active in organizing a timebank in Finland. Through them, we are able to illustrate how their community has struggled with horizontality. Their explicit wish to organize without creating a bureaucracy, while simultaneously resisting oligarchization, and their continuing struggle to do so, provides the opportunity to expand upon earlier studies of organizing in social movement initiatives (e.g., Blee, 2012; Dobusch \& Schoeneborn 2015; Freeman, 1972; Sutherland, Land, \& Böhm, 2014). In this chapter, we explore how they sought to navigate between decided and emergent social order. 


\section{THE INSTABILITY OF ORGANIZATION}

Several ideas that challenge traditional assumptions of organization have emerged in organization theory over the past few years (Böhm, 2006; den Hond et al., 2015; Parker et al., 2014). This research commonly points to the myopia related to understanding organization as a constituted formality, as a way of organizing that is presumably politically neutral and functionally efficient (if not also morally superior; du Gay \& Vikkels $\varnothing, 2016$ ). By pointing out and exploring the possibility of alternative organization (Parker et al., 2014), it criticizes the idea that social organization seems always already formed, predetermined and given (Böhm, 2006: 5). Partial organization theory represents a possible way of adding to this literature by problematizing the choices that are inherent in and behind any decision to modify social order.

Formal organizations, the topic of study for the classical writers of organization theory, are characterized by extensive decision making on five elements of organization: membership, hierarchy, rules, monitoring, and sanction. (See Chapter 1.) For two reasons, however, social order in organizations cannot be characterized solely by or understood as decided social order. First, social order in organizations is not only decided, but also simultaneously emergent; emergent social order stems from the relationships (networks) among members and from their shared beliefs, identity, and behavioural patterns (institutions). Second, there is the possibility that people in organized settings (organizations, collectives) forgo the possibility of decision making on one or more of the elements of organization and rely instead on emergent sources of social order for coordination and collaboration. We understand partial organization to be descriptive of the temporary and evolving pattern or mixture of emergent and decided sources of social order 
(Bor \& den Hond, 2015) in settings in which people collaborate to accomplish some common purpose.

As a legacy from the classical writers, traditional views of organizing have rested on assumptions of unity, unequivocality, and goal specificity, to which Herbert Simon added the prime importance of decision making. By contrast, partial organization theory does not need to rely on these assumptions if it problematizes decision making and takes seriously the possibility of relying on emergent social order as a means of co-ordinating collaboration. Although in an overall sense, some decision making - and therefore a decided social order seems necessary for organization to happen or to be meaningful, the necessity of specific instances of decision making can always be challenged. A decision or proposal for a specific form or element of decided social order can be rejected, other decisions considered and preferred, or no decision made (a non-decision; Bachrach \& Baratz, 1963). Whereas one can imagine some (collaborative) social setting in which social order does not depend on decision making (Berger \& Luckmann, 1967: 70-ff), we cannot imagine any instance of organization in which there is no emergent social order. In this sense, organizing - rather than organization - needs to be understood as decision making in order to affect the prevailing social order, an intervention in the then-present mixture of emergent and decided sources of social order. Organization is thus inherently unstable not only because changing conditions in the environment demand decision making, but also because the relationships between organizational participants evolve over time, as do their shared beliefs, identity, and behavioural patterns. Emergent social order evolves for various reasons: in reflexive response to the prevailing social order, in reaction to decision making that seeks to affect it, and autonomously (cf. Tsoukas \& Chia, 2002). 
The participants of many contemporary social movement initiatives attempt to practice horizontality: a form of organization that is democratic and inclusive in participation and that eschews authority, leadership, and structure among the characteristics of formal organization. Proponents of horizontality shun Weberian legal-rational and traditional authority, as embodied in hierarchy and, by extension, in the other elements of organization. Their preferred social order is prefigurative (Boggs, 1978), inasmuch as they attempt to show the promise of their horizontal ideal in present action. Indeed, their modus operandi is to expose the possibility of another societal order. Activists and activist groups are pivotal in 'turning a critical lens on what is and imagining what can be' (Blee, 2012: Acknowledgements, emphasis in original), in relation to organizing and decision making, for example (Maeckelbergh, 2011; Teivainen, 2016; Yates, 2015). Thus, in terms of partial organization, they may refuse to distinguish between members and non-members, to privilege some participants with the right to instruct other participants, and to constrain individual responsibility and choice through rules and through systems of monitoring and sanctioning.

However, horizontal organizing and avoidance of decided social order may not prevent the emergence of a social order in which a few participants establish hegemonic power over the many. Nor does it resolve the challenge of maintaining an open, participatory style of decision making and co-ordination (Clemens \& Minkoff, 2004). The instability of organization in social movement initiatives can thus lead to two types of outcomes. There may be an accumulation of decision making, such that they eventually come to resemble bureaucracies (bureaucratization, e.g., Graeber, 2015), or there may be an accumulation of authority, and eventually the usurpation of social order by a minority of 
participants (oligarchization, cf. Leach, 2005; Michels, 1965; Tolbert \& Hiatt, 2009; Zald \& Ash, 1966).

The participants in social movement initiatives explore the possibility of resisting both bureaucratization and oligarchization. If they wish to remain horizontal, they must stay clear of two tendencies. First, they need to resist the tendency to rely increasingly on decision making as the main source of social order in their initiative, if they do not want to end up mimicking the characteristics and rigidities of a bureaucratic organization (cf., Ahrne \& Brunsson, 2011; Reedy, 2014). Second, they must resist a tendency towards the institutionalization of social practices and relationships that confirm differences in status and that may eventually result in oligarchy. In recognition of the risks of both bureaucratization and oligarchization, extensive experimentation with horizontal organization has taken place (Graeber, 2013; den Hond et al., 2015; Reinecke, forthcoming). Horizontal, prefigurative organization does not represent a clear-cut model of organization, but rather an ideologically informed experiment. Being ideological, it effectively leaves the organizational question unanswered beyond the rejection of a decided social order and a handful of general guidelines, such as how to achieve consent within a group.

\section{The HeLSINKI TIMEBANK}

In this section, we analyse the organizing of Stadin Aikapankki (STAP: Helsinki Timebank). Our analysis draws on data that we collected as part of an on-going larger-scale ethnographic investigation on how local communities build alternative economies. The data utilized here include semi-structured interviews conducted between March and May 2015, archival materials (internal documents, some available through the Internet), the timebank's electronic workspace, and field notes from participant observation and informal 
conversations. We interviewed 11 participants in what STAP members refer to as the 'core group'. Some interviewees have been active in STAP, others joined later, and some interviewees had recently ceased active participation in the core group. The first author took field notes between March 2015 (when he joined STAP and became involved in the work of the core group) and October 2016. The lived experience of being an outsider to the community with the intention of becoming an insider proved valuable in understanding the interviewees' accounts of their experiences with STAP. Given the close connectedness of the core group of individuals, we dealt with issues of respondent privacy (Clark, 2006) by assuring full anonymity to the interviewees.

We first introduce STAP as partially organized. We then highlight two episodes in which the organizational question became prominent, and finally present its outcomes or, rather, how the organizational question remained unresolved.

\section{STAP as partially organized}

Our empirical case of STAP is a local alternative currency community operating in metropolitan Helsinki, Finland, since 2009. Its currency is the tovi: a play on words. (The Finnish word 'tovi' translates as 'a while', or 'a moment'.) One tovi has the value of one hour of work: Sellers receive one tovi as a credit for every hour of work they render to other members of the community (the buyers of the sellers' services), and in turn, sellers become buyers when they spend their credit on services from other community members. The exchange rests on generalized reciprocity: Community members are not required to 'buy' services from the people to whom they previously 'sold' their service; rather, they are expected to offer and exchange services actively with anyone in the community.

There were two types of motivations for the creation of STAP. On the one hand, it was an attempt to increase the wellbeing of its individual participants, the community of 
participants, and ultimately the greater common good of the city. On the other hand, it was an attempt to develop and experiment with a variety of alternative social, economic, and environmental practices to the dominant capitalist framework (Alhojärvi et al., 2015; Laamanen et al., 2015). In combination, they show how STAP is a truly prefigurative social movement initiative aimed at developing a communal culture for a socially and ecologically just local economy, in which every person has equal value and opportunity to participate. STAP adheres to two principles: stigmergy and adhocracy. Stigmergy relates to the organizing of work, whereas adhocracy stands for a decision-making mechanism. Stigmergy is the collectively negotiated, distributed action of independent actors (Elliott, 2006). In STAP, this translates into work being distributed through self-organization as members sign up for and execute tasks when they observe that tasks need to be done. The core group's online electronic workspace and e-mail list are means by which members facilitate stigmergy. Adhocracy is the flexible and situational organizing for decision making, to allow for maximum participation and minimum specification of authority. Adhocracy is practiced most pronouncedly in the membership meetings, in which those members present have the power to pass decisions. The distribution of work through stigmergy is subject to adhocratic decision making, for example, to prevent the accumulation of power and to allow everyone to join decision-making processes at any time they participate in the group. On this basis, STAP has prevented itself from becoming an organization in the traditional meaning of the word. STAP deliberately chose not to register as an association, which, in the Finnish context, would have implied an obligation to define and assign organizational roles, tasks, and responsibilities. STAP members saw these implications as the imposition of hierarchy that would be incompatible with its principles of stigmergy and adhocracy. 
In some ways, however, STAP did introduce organizational elements, albeit minimally. Participants must be registered as members to be able to exchange services in the timebank. Yet, STAP has made it easy for new members to join; anybody can participate by registering through its website. An administrator, a core group member who is entrusted with the task, processes new membership applications. In the process, the administrator checks only the validity of the information provided. Becoming a member, then, is a straightforward process: a routine administrative operation rather than a decision on individual applications. This process is not without its problems, as a former administrator elaborates:

As our member register has over 3,500 names, I'm not sure if most of these [members] even remember that they ever became members. I sometimes get requests for account openings from people with existing accounts ... The personal details are generally not checked [when an account is opened] ... Should I open an account, if Donald Duck registers as a member and gives Duckburg as the address? Technically, it [registering as a member] does not require more than a name, address, and e-mail.

The exchange of services among STAP members is subject to the acceptance of a shared set of norms and rules. Some rules relate to the overall administering and functioning of STAP, such as the build-up of a community fund through a levy on all transactions. The community fund is used mainly to reimburse members for services delivered to the collective. Others are essentially norms: shared expectations of appropriate behaviour within the community. 
Monitoring and sanctioning are delegated to members rather than being centralized and enabled through transparency. STAP was founded in October 2009, and by October 2017 , more than 14,200 transactions to a value of little over 34,000 tovi had been administered on an online platform. Exchanges are facilitated through the distribution to STAP members of monthly listings of offerings and requests. To increase transparency and trust and to ensure that members' debits are under the allowed maximum of 50 tovi, every member has full access to all other community members' details and to all the exchanges registered on the online platform.

As tovi are not convertible to monetary currencies, amassing tovi is not economically rational. Nevertheless, some members maintain accounts with substantial surplus balances (+200 tovi), which they justify in membership meetings as not having any needs but a great willingness to help (and perhaps anxiety for receiving help, cf. Papaoikonomou \& Valor, 2016). If a member has a deficit of more than 50 tovi, a core group member is mandated to contact this member and offer support to start providing services in the community. In extreme cases, the members can decide to reset the overdrawn account to zero, drawing on the community fund.

Sanctioning rarely happens. Members are advised to resolve between themselves any disagreement about the timeliness or the quality of service delivery. If members are unable to resolve the disagreement, an appointed team may mediate. Such mediation is participatory and conciliatory:

Conciliation has been used very little ... I don't see that this is a sanctioning mechanism [but] meant for people to find a common solution ... We [the conciliators] do not take a stance on what is right and what is wrong, we let the people talk to one another ... We don't take a stance on who is lying and who is not 
... We have rules for exchange; they are beginning to be quite exhaustive ... I'm that kind of a bureaucrat that some intervention process has to be created ... I don't know how this could work without rules.

The membership meeting, the supreme decision-making body of the collective, has effectively relegated operational discretion to specific individuals in their role of administrator or as members of the core group. They do not acquire the right to command others, however, because STAP has no hierarchy. Yet, the regular administration of tasks by specific individuals offers them the possibility of wielding tacit forms of power (cf. Breton et al., 2012). In the spring of 2010, an e-mail list and an electronic workspace were created for a core group of people who participate more actively than regular members in the administration of STAP. The group is in charge of initiating and maintaining such activities as accepting new members; creating the newsletter; organizing membership meetings, exchange markets, and community events; and promoting the timebank to potential members. At its largest, the core group had around 40 members; the current core group consists of 21 people. In principle, every member of STAP can step forward and become part of the core group, but relatively few have done so.

All STAP members receive an invitation to participate in meetings, but in practice, often only a handful of people attend. Decision making during the membership meeting is noteworthy, because decision-making power has always been adhocratic. Decisions are relative only to and limited to a specific meeting, with the possibility that the next meeting overrules a previous decision. Adhocracy renders decision making non-representative: 
Neither our meetings nor the core group has ever been representative in any way.

Or rather, not representative of the entire membership or legitimized by anyone in particular. We have not chosen any representatives. People [represent] themselves.

There are few if any recurring items on the agenda of the membership meetings. The agenda is distributed just before the meeting and is often amended during the meeting. Over the few past years, the agenda included such topics as participation in events and collaborations with external entities, including the City of Helsinki and other solidarity/alternative economy groups. One core group member expressed her mounting discontent about the way membership meetings are run and with their composition, as 'random samples' of the most 'random people' of the collective's membership are typically present:

We should have a long-term perspective on thinking about how to deal with the global responsibility strategy of the City of Helsinki [in which timebanking is mentioned as a key development area]. Then along comes the membership meeting, where we spend an hour on [issues such as] logging in to the [online] platform, baking cakes for the next meeting, and such ... There are those who have strong opinions on whichever random issue. There's someone who thinks that we need to start purging members, whatever. It can be anything. There is no continuity.

Thus, in spite of its members not wanting STAP to be an organization, various elements of decided social order are present. Membership was introduced early on, albeit in a weak form. The creation of the core group can be seen as the introduction of some form of authority. But otherwise, there has been little, if any, decision making on rules, 
monitoring, and sanctions. Among these elements of organization, only membership was fully accepted; other elements remained controversial and were occasionally contested or just ignored.

At the same time, the lack of decided social order remained equally controversial. Although in theory stigmergy should reduce the need for decided social order within STAP, in practice it has remained problematic and contested. A member of the core group concludes:

Stigmergy is not written down anywhere ... To some extent I think that this is part of [one central actor's] ideological background ... A way to do things organically, to grow and develop in a common learning process ... I think, however, that it will be a thousand years [until true stigmergy is realized]. Maybe I am a bit impatient, but I want to do things here and now.

In what follows, we illustrate how STAP struggled with organizational form and authority; how on the one hand it perceived a need for decided order, while on the other hand attempting to keep it at arm's length.

\section{ORGANIZATIONAL DYNAMICS IN STAP}

Of particular interest for partial organization in this local social movement initiative is the formation of authority and the maintenance of horizontality, which relate to 'situations and patterns or interactions between organizers and the organized that give rise to more or less organization' (Ahrne \& Brunsson, 2011: 95). The impetus for collective contemplations on organizing emerged from two highly salient issues: an internal issue, relating to the growth of the initiative in terms of membership; and the other external, relating to the prospect of 
having to comply with rulings of the Finnish tax authorities. Table 1 offers a timeline of major events in the history of STAP. It serves as a background to the subsequent episodes.

Table 1. STAP development timeline

\begin{tabular}{|l|l|}
\hline October 2009 & The predecessor to STAP is founded with a membership of 5 individuals \\
\hline Spring 2010 & First membership meeting; formation of the core group \\
\hline May 2010 & Mapping of STAP values \\
\hline November 2011 onwards & Increasing public exposure of the initiative \\
\hline 2012 & Rapid increase of membership \\
\hline March 2013 & Discussion: 'Why do we need STAP?' \\
\hline May 2013 & Introduction of ABC \\
\hline June 2013 & Tax investigation \\
\hline September 2013 & Tax instruction draft and STAP statement \\
\hline November 2013 & Official tax instruction \\
\hline February 2014 & Meeting to discuss organizational form \\
\hline June 2014 & Co-ordinator reaches out to the City of Helsinki \\
\hline May 2016 & Seminar: 'Let's s Save the Timebanks' \\
\hline
\end{tabular}

Membership, growth, and rules

In its early days, STAP was a 'rather unorganized activity', and equality and inclusiveness were central to its horizontal operating practice. As one member elaborated: 
When they founded the timebank, it had four housewives as members who decided amongst themselves to exchange [the equivalent of] tovi for babysitting for each other ... back then adhocracy probably worked quite well. It would have been stupid to set up an administrative body or an association or something else.

In accordance with the practice of horizontality, articulated as stigmergy and adhocracy, administrative tasks were to be distributed among the individuals who signed up to perform them. As STAP membership grew exponentially, however, from the initial group of a handful of acquaintances and friends in late 2009 to around 3,300 in 2017, this model exhibited its limits. It was in the face of a growing membership base that it was agreed at the 2010 membership meeting to create an e-mail list for the core group of people who did most of the co-ordination of the tasks associated with operating the timebank. This model worked for some time with the core group, but co-ordination became an issue again in late 2012, when STAP observed its strongest growth in membership.

Certain problems can be identified, as the following quote illustrates: 'In practice, work got done because there was a particular core group, albeit vaguely formed and compositionally mutable' (Membership meeting minutes, 2 February 2014). Indeed, there were no appointed roles or responsibilities beyond those assumed by the core group. In practice, routine work fell onto this small group of individuals, particularly one of the founding members. Limiting action to spontaneous enrolment created de facto barriers to participation by those members who wanted to become more active. Active members had more knowledge about what was going on, what was needed, and what had been done, and they had the contacts required to administer the timebank effectively. This situation led to an increasing separation between the core group and the rank-and-file members, whose 
marginalization was further enhanced as new members found it difficult to integrate into STAP. Many new members were less ideologically motivated than the initiators were and had less intuitive understanding of STAP's practice of horizontality.

With the increase in membership and a growing heterogeneity in members' motivations to participate, discussions began on ways of explicating the norms and practices of horizontality to new members, ways of aligning new members' values and identities with those of STAP, and ways of developing mechanisms for socializing new members into the network. The membership meeting agreed on the articulation and publication of the values and practices that underlie STAP's identity.

In 2013, STAP created a document entitled ABC. It outlined the identity and purpose of the community in its key practices and values, a tovi etiquette for exchanges and interactions, and STAP's ways of working and decision making. Introduction of the ABC followed a perceived need to explicate the community's values, such as horizontality, solidarity, and inclusion, as rooted in the alternative economy movement. Formulating the $A B C$ was a demanding process. Core group members recounted intense, heavily debated discussions on content. Two factions had formed, their division cutting through both the core group and the regular membership. One faction emphasized the ideological outlining of STAP and regularly referred to the way the collective is embedded in the solidarity economy convictions of the founding members. The other faction was more pragmatic and attentive to the actual trading practices and to how trading in in the community may be stimulated and facilitated.

Ultimately, the $A B C$ serves to inform prospective members about STAP's goals, how the timebank works, and the norms and rules it adheres to. (Although written in the imperative, tovi etiquette is seen merely as suggesting correct behaviours). Supporting the 
familiarization processes of new members and opening access to administrative work in the core group was aimed at removing any significant hindrances to participation. Upon joining STAP, new members are requested to read the ABC. Nevertheless, as one core member said, 'We don't seem to do a good job of introducing people to the ways of working in the timebank'. Thus STAP was in a situation in which the membership meeting became the de facto introductory event, and the community's rules lost some of their significance. As one member illustrated:

[Membership meetings] always start with the basics, as there is always someone there to ask how to use the timebank ... knowing nothing and then there are those who have been there the whole time ... [the meetings] go through the same issues every time and that begins to frustrate people.

Thus, as the membership of STAP increased, members began to realize that their way of co-ordinating tasks and responsibilities had its limits. This was resolved, first, through the creation of the e-mail list and electronic workspace for members who wanted to take responsibility for co-ordination and administration. But even within this core group, there were significant differences in the level of activity of its participants. As membership began to increase significantly, there was a decrease among new members in the awareness of and identification with the timebank's practices. The $A B C$ and the tovi etiquette it contains is an effort to make explicit the norms that underlie the practices of the timebank: rules, but not rules that are backed up with monitoring and sanctions. A second consequence of growth was that authority became concentrated within a relatively small group of people, not because they sought to dominate the timebank, but because of the scale and speed of 
growth, and, as Breton et al. (2012) describe, the participants that do assume such responsibilities tend to become entrenched as leaders and distinct from other participants.

\section{Expectation of compliance}

The second major episode actualizing STAP organizing came from external sources. In the years of substantial growth between 2010 and 2013, STAP received extensive media coverage in the Finnish mainstream media. The community was included in various processes, such as the City of Helsinki's development of a strategy of global responsibility. Consequently, political interest and discussion around initiatives in the alternative economy were in high gear.

In spite of the positive press and political appraisal of its initiative, the community eventually came under investigation by the Finnish tax authorities as part of their shadoweconomy prevention. The Finnish tax authorities released a report outlining work in the community entitled 'Timebanking in Finland' in June 2013 and, consequently, a tax official asked for a response from STAP. Much of the input of active members was aimed at attempts to counter the possible adverse effects of a pending tax decision, particularly if it were hostile to the activities in the community. The activities also revealed tensions in the way administrative work in the community was being conducted.

When the tax officials came to us for an official statement, it would not have happened through spontaneous churning [i.e., adhocratic decision making]. Then we had to work in a very structured way to formulate our stance. If I had done it by myself, it would have been quite different. I would have addressed each section [each tax official's argument]. 'The tax official thinks this; I answer thus.' ... But [our statement] became vague. It was a compromise, and at 10 past 4 , with a deadline at 15 past 4 on the [same] day, people started to debate on foundational things. At this 
point I said, 'Not now. Now we finish this paper.' It can be that sometimes we need a tougher [authority/structure], and sometimes a more creative and spontaneous movement.

In November 2013, the tax authorities made a decision on the taxation of voluntary work by natural persons. The tax authorities' decision was a severe blow to the community, as it departed significantly from the June report and the suggestions made by STAP in its response to the report. The decision caused confusion amongst the community's participants. Whereas tax liability relates only to professional work performed in the community, many participants decided to stop engaging in exchanges, in order to avoid any adverse tax consequences. The effects of the tax authorities' decision and the community's work in taking a stance took their toll on participation. As one core member said:

Now I feel that with all this effort around tax, activity has collapsed, faded away. Part of the community is afraid of any tax consequences. I don't know if it's also some kind of combat fatigue. For my part, maybe it's just that. Not sure if a new rise is coming after this slump. It's slumped all right; for instance, when [a core group member] gets excited and sends a message to the core, it's very few that react to these nowadays.

As a result, there was a significant decline in new membership applications and exchanges. Frustration mounted within the core group as their attempts to influence official decisions turned out to have been in vain. The tax decision effectively paralyzed active participation both in the core group and in STAP more generally, but it also revitalized the conflict around ways of organizing. 


\section{Non-decision on a new constitution}

The intense periods of work on community rules and dealing with the tax issue led to the build-up of tensions within the core group. As one founding member said:

I did a lot of lobby work for our proposal to the tax official. But what happened was a shock to all of us. We were disappointed and frustrated, and this started to affect people. The end of 2013 was a hostile period, with more or less open conflict ... There was some debate on the STAP list, and I know that people in smaller groups were talking behind each other's backs ... I was given feedback on what I had done wrong, what I should not have done, and that sort [of thing] ... My answer was that we should think about this organizational stuff, and in February 2014 we had this meeting [on organizational form]. I remember it being a little traumatic.

This founding member's experience convinced her to step down from active membership in the core group. The mainstay of the critique that emerged was that an implicit authority had developed over the years around the founding members, whose functions, responsibilities, and ownership of the timebank had effectively made them indispensable in decision making. This situation was not without its problems. As one core member explains, those who participated in the discussions with the tax authorities had self-selected (e.g., they had the time and energy to engage in this work), but lacked legitimacy and a mandate from the community, which the authorities expected them to have.

To address this authority issue, a membership meeting in February 2014 focused on the question of organizational form. The pros and cons of two opposing structural alternatives - adhocracy and hierarchy - were extensively discussed: What would they 
imply for such topics as decision making, members' responsibilities, and STAP values? The members at the meeting also discussed gender imbalances between a male-led structure and a fluid community, in which the main responsibility for work fell onto the female membership. Yet, the conflict between the two alternatives is less than obvious, given that ease of decision making was considered a positive feature of both, for instance.

No decision could be met during the meeting, and organizational discussions withered soon after. The minutes of the February 2014 meeting state that the 'organizing matrix' was shared on the community website for the membership to comment on and continue work with. Sharing the matrix with the membership was aimed at generating an inclusive conversation. Only one comment has since been posted on the thread, however; it critiqued the preoccupation with form in favour of a model with a function-driven (rolebased) approach to organizing (i.e., bureaucracy). Thus, lack of clarity around the organizational form continued, as did the conflicts between proponents of more rules and a constitution and those preferring to work in a strictly horizontal manner.

In the face of all this disagreement and non-decision, two noteworthy interventions occurred in May 2014: A co-ordinator role was created, and the core members were explicitly asked if they would be willing to continue in their roles.

The first intervention was the creation of a co-ordinator role. This decision was a compromise, intended to maintain a fluid, light hierarchical structure and to help get things done.

It was May [2014], if I remember correctly, in a membership meeting that we decided that, according to the organizing discussion, we would need a co-ordinator. An appointed co-ordinator. The only person who was willing was [the current coordinator]. ... But this is the thing. In this work, you would need a strong person 
[laughs] to be an initiative-taking co-ordinator ... I feel that [the current co-ordinator] had done really valuable practical work ... [but] they have not become a powerwielding co-ordinator.

The intention of the second intervention, asking core members if they wanted to remain, was initiated in order to support active participation in the core group by letting the core members decide if they still wanted to contribute. About half of them decided not to continue, and the group was reduced to 20 members. A founding member recollects:

All of last spring, I did nothing; nor did anyone else. And so that conversation [on organizing] was just discarded. And then I gave justification [for my noninvolvement], as I had to finish my dissertation, but also to see what would happen if I retreated. Whether someone takes that space ... I said to [another founding member] in one message: 'What if we both just quit? Would it not be inclusive when we would say, hey, if you complain that we use too much power, use it yourselves? Now, take it and occupy it, like that.' And I must have written on the list a message that I would be taking to the side-lines, and hope that somebody else would take [centre stage].

In order to maintain the community despite these various conflicts, there have recently been several attempts at member activation, such as reintroduction of regular membership meetings and attempts to build collaboration with the City of Helsinki (particularly through a seminar held in 2016. Thus attempts were made to rebuild the community internally, while continuing to turn a blind eye to the question of organization and to mobilizing external actors to legitimize timebanking as a pro-social activity. 


\section{THE INSTABILITY OF PARTIAL ORGANIZATION}

This chapter has highlighted a setting in which organization in the form of decision making under hierarchy, rules, monitoring, and sanctioning is unwanted. It expands recent conceptual discussion on partial organizing in social movement initiatives (de Bakker et al., 2017) by demonstrating empirically why organization is or is not introduced, and why and how it remains partial. By asking how these timebank members attempted to practice horizontality, we set out to examine the way they produced organization at the intersection of their ideological avowal to horizontality in prefiguring an inclusive social order of the economy, on the one hand, and their struggle to resist bureaucratic and oligarchic tendencies in their organizing, on the other hand. We illustrated their decision not to make decisions and their inability to do without a decided social order. Their organizing was incremental, triggered by both internal (growth in membership) and external (intervention by the tax officials) events.

STAP exhibits several characteristics of partial organization. On the preceding pages, we particularly dealt with the ways in which expectations for both stigmergy/adhocracy and authority emerged and occasionally resulted in decision making. The case of STAP demonstrates the activation of some elements of organization, such as establishing the core group, creating the $A B C$, and defining the position of co-ordinator. Other elements of organization were plainly rejected, particularly by those members whose approval seemed to count most. Thus, elements of decided order remained contested; the vesting of authority in specific individuals was not permanent and a hierarchy was not introduced. The $A B C$ is a clear example of the introduction of organization - of decided social order - into the emergent social order. Membership growth and the resulting lack of familiarity with the 
workings of STAP among new members made it necessary to guide the behaviour of members, which led to the creation of rules in the form of stated values and a code of conduct.

Tensions in the community remained, as some active members criticized the few individuals who did most of the work, saying that they wielded too much power. Yet the criticizing members were unwilling to assume responsibility. Interventions to introduce more decided social order faltered and no decision on organizational form was made. The two factions that wanted different degrees of organization began to challenge each other, a pattern not uncommon in social movement initiatives (Sutherland et al., 2014). In many groups, there is a small number of participants that assume group-level responsibilities, thereby generating distinction for themselves and dependency in others. Yet, their central position in leading and decision making render them targets of criticism (Breton et al., 2012). If the criticism is dismissed, suppressed, or ignored, groups may evolve towards oligarchy. Freeman (1972) warned against the 'tyranny of structurelessness', whereby nobody is responsible or accountable, and those with central positions can gain a great deal of tacit power.

Sutherland and his co-authors (2014) suggest that the tendency to oligarchization, stemming from differences in knowledge and capability among participants, inequalities in gender structures, or collaboration in cliques, is neither insurmountable nor inevitable. Continuous reflective practices and willingness to learn would be key factors in fostering a more equal and collective authority. When roles of collective responsibility are rotated among participants, for example, and when participants are stimulated to develop and exercise their skills in collective responsibility, they may evolve towards a mode of organizing that is closer to their ideal of horizontality (cf. Sutherland et al., 2014). Such 
reflective practices were not enacted in STAP. Nevertheless, our interviews and observations suggest that at least the members of the core group were aware of the authority issues at stake, but they were unable to agree on how to move forward. Although its horizontality was not without problems, STAP did not develop into either a bureaucracy or an oligarchy. Its members are expected to steer, manage, and undertake activities collectively, yet the core group, whilst open to all members, was seen as a selective group that, due to their engagement, wielded a tacit, privileged form of power.

We highlighted the critical juncture in the practicing of stigmergy and adhocracy at STAP, when those who came to wield power become subjects of criticism, and rank-and-file participants experienced the flipside of this situation. Horizontality may produce marginalization for ordinary members and render it difficult for new members to participate. As one participant commented:

Every timebanker joining [STAP] feels like an outsider for a very long time. In fact, most timebankers feel more or less like outsiders, because there is a very small group of people that have done a lot ... and maintained intensive involvement [they were] insiders enough to do something.

The idea of horizontality sustains the current unstructured situation at STAP. The conflict for participants is that adhocratic decision making is manifestly open to everyone and can be influenced by any participant, yet the ultimate approval for decisions and courses of action is sought from a few individuals. Problematically, this form of authority alienated some active members, who then left the core group. Others voiced their concerns and suggested an organization between decided and emergent order.

In conclusion, we are advancing the argument that the partial organization in many local social movement initiatives is ridden with tension. As we have demonstrated with the 
case of STAP, these tensions were created by a need for organizing and a principled resistance to the establishment of social order through organizational elements.

\section{REFERENCES}

Ahrne, G., \& Brunsson, N. (2011). Organization outside organization: the significance of partial organization. Organization, 18(1), 83-104.

Alhojärvi, T., Ryynänen, S., Toivakainen, N., \& van der Wekken, R. (2015).

Solidaarisuustalous. In M. Jalonen, \& Silvasti, T. (Eds.), Talouden uudet muodot (pp. 210-230). Helsinki, FIN: Into.

Bachrach, P., \& Baratz, M. S. (1963). Decisions and nondecisions: An analytical framework. American Political Science Review, 57(3), 632-642.

Berger, P. L., \& Luckmann, T. 1967. The Social Construction of Reality: A Treatise in the Sociology of Knowledge. New York, NY: Doubleday.

Blee, K. M. (2012). Democracy in the Making. How Activist Groups Form. Oxford, UK: Oxford University Press.

Boggs, C. (1978). Marxism, prefigurative communism, and the problem of workers' control. Radical America, 11/12(1), 99-122.

Bor, S., \& den Hond, F. (2015). Social order \& organisational dynamics. Working paper. Presented at the 4th European Theory Development Workshop, Cardiff, 24-25 June 2015.

Breton, E., Jeppesen, S., Kruzynski, A., \& Sarrasin, R. (2012). Prefigurative self-governance and self-organization: The influence of antiauthoritarian (pro)feminist, radical queer, and antiracist networks in Quebec. In A. Choudry, J. Hanley, \& E. Shragge (Eds.), 
Organize! Building from the Local for Global Justice (pp. 156-173). Oakland, CA: PM Press.

Böhm, S. (2006). Repositioning Organization Theory. Basingstoke, UK: Palgrave Macmillan. Clark, A. (2006). Anonymising Research Data (NCRM Working Paper 07/06). Southampton, UK: National Centre for Research Methods. Retrieved June 9, 2015, from http://eprints.ncrm.ac.uk/480/.

Clemens, E. S., \& Minkoff, D. C. (2004). Beyond the Iron Law: Rethinking the place of organizations in social movement research. In D. A. Snow, S. A. Soule, \& H. Kriesi (Eds.), The Blackwell Companion to Social Movements (pp. 155-170). Malden, MA: Blackwell.

de Bakker, F., den Hond, F. \& Laamanen, M. (2017). Social movements: Organizations and organizing. In C. Roggeband, \& B. Klandermans (Eds.), Handbook of Social Movements Across Disciplines (pp. 203-231). Cham, CH: Springer.

den Hond, F., de Bakker, F. G. A., \& Smith, N. (2015). Social movements and organizational analysis. In M. Diani, \& D. della Porta (Eds.), The Oxford Handbook of Social Movements (pp. 291-305). Oxford, UK: Oxford University Press.

Dobusch, L., \& Schoeneborn, D. (2015). Fluidity, Identity, and Organizationality: The Communicative Constitution of Anonymous. Journal of Management Studies, 52(8), 1005-1035.

du Gay, P., \& Vikkelsø, S. (2016). For Formal Organization: The Past in the Present and Future of Organization Theory. Oxford, UK: Oxford University Press.

Elliott, M. (2006). Stigmergic collaboration: The evolution of group work. M/C Journal, 9(2). Retrieved December 26, 2017, from http://journal.media-culture.org.au/0605/03elliott.php/. 
Eskelinen, T. (2014). Aikapankkien yhteiskunnalliset vaikutukset ja verotus. Helsinki, FIN: Vasemmistofoorumi.

Freeman, J. (1972). The tyranny of structurelessness. Berkeley Journal of Sociology, 17, 151165.

Graeber, D. R. (2013). The Democracy Project. A History. A Crisis. A Movement. London, UK: Penguin.

Graeber, D. R. (2015). The Utopia of Rules. On Technology, Stupidity, and the Secret Joys of Bureaucracy. Brooklyn, NY: Melville House.

Laamanen, M., Wahlen, S., \& Campana, M. (2015). Mobilising collaborative consumption lifestyles: A comparative frame analysis of time banking. International Journal of Consumer Studies, 39(5): 459-467.

Leach, D. K. 2005. The iron law of what again? Conceptualizing oligarchy across organizational forms. Sociological Theory, 23(3): 312-337.

Maeckelbergh, M. (2011). Doing is believing: Prefiguration as strategic practice in the alterglobalization movement. Social Movement Studies: Journal of Social, Cultural and Political Protest, 10 (1), 1-20.

McCarthy, J. D., and Zald, M. N. (1977). Resource mobilization and social movements: A partial theory. American Journal of Sociology, 82(6), 1212-1241.

Michels, R. (1965 [1911]). Political Parties: A Sociological Study of the Oligarchical Tendencies of Modern Democracy. New York, NY: Free Press.

North, P. (2014). Complementary currencies. In M. Parker, G. Cheney, V. Fournier, \& C. Land (Eds.), The Routledge Companion to Alternative Organization (pp. 182-194). London, UK: Routledge. 
Papaoikonomou, E., \& Valor, C. (2016). Exploring commitment in peer-to-peer exchanges: The case of timebanks. Journal of Marketing Management, 32(13-14), 1333-1358. Parker, M., Cheney, G., Fournier, V., \& Land, C. (2014). Imagining alternatives. In M. Parker, G. Cheney, V. Fournier, \& C. Land (Eds.), The Routledge Companion to Alternative Organization (pp. 31-41). London, UK: Routledge.

Reedy, P. (2014). Impossible organizations: Anarchism and organizational praxis. ephemera: theory \& politics in organization, 14(4), 639-658.

Reinecke, J. (forthcoming). Social movements and prefigurative organizing: Confronting entrenched inequalities in Occupy London. Organization Studies, conditional acceptance.

Sutherland, N., Land, C., \& Böhm, S. (2014). Anti-leaders(hip) in social movement organizations: The case of autonomous grassroots groups. Organization, 21 (6), 759781.

Teivainen, T. (2016). Occupy representation and democratise prefiguration: Speaking for others in global justice movements. Capital \& Class, 40(1): 19-36.

Tolbert, P. S., \& Hiatt, S. R. (2009). On organizations and oligarchies. Michels in the twentyfirst century. In P. S. Adler (Ed.), The Oxford Handbook of Sociology and Organization Studies: Classical Foundations (pp. 174-199). Oxford, UK: Oxford University Press.

Tsoukas, H., \& Chia, R. (2002). On organizational becoming: Rethinking organizational change. Organization Science, 13(5): 567-582.

Yates, L. (2015). Rethinking prefiguration: Alternatives, micropolitics and goals in social movements. Social Movement Studies: Journal of Social, Cultural and Political Protest, 14 (1), 1-21. 
Zald, M. N., \& Ash, R. (1966). Social movement organizations: Growth, decay and change. Social Forces, 44(3), 327-341. 